University of Wollongong

Research Online

Faculty of Engineering and Information

Faculty of Engineering and Information

Sciences - Papers: Part A

Sciences

$1-1-2015$

\title{
A multi-objective design optimization strategy for vertical ground heat exchangers
}

Su Huang

University of Wollongong, sh377@uowmail.edu.au

Zhenjun Ma

University of Wollongong, zhenjun@uow.edu.au

Fenghao Wang

Xi'an Jiaotong University

Follow this and additional works at: https://ro.uow.edu.au/eispapers

Part of the Engineering Commons, and the Science and Technology Studies Commons

Research Online is the open access institutional repository for the University of Wollongong. For further information contact the UOW Library: research-pubs@uow.edu.au 


\title{
A multi-objective design optimization strategy for vertical ground heat exchangers
}

\author{
Abstract \\ A multi-objective design optimization strategy for vertical U-tube ground heat exchangers (GHEs) is \\ presented to minimize the system upfront cost and entropy generation number simultaneously. Five \\ design variables of vertical U-tube GHEs, including borehole number, borehole depth, borehole radius, U- \\ tube outer radius and fluid mass flow rate, are first selected via a global sensitivity analysis method, and \\ then optimized by a genetic algorithm (GA) optimizer implemented in MATLAB. Based on the Pareto \\ frontier obtained from the GA optimization, a decision-making strategy is then used to determine a final \\ solution. Two case studies are presented to validate the effectiveness of the proposed strategy. The \\ results based on a small scale GSHP system in Australia show that, compared to the original design, the \\ use of this proposed strategy can decrease the total system cost (i.e. the upfront cost and 20 years' \\ operating cost) by $9.5 \%$. Compared to a single-objective design optimization strategy, $6.2 \%$ more energy \\ can be saved by using this multi-objective design optimization strategy. The result from a relatively large \\ scale GSHP system implemented in China shows that a $5.2 \%$ decrease in the total system cost can be \\ achieved by using this proposed strategy, compared with using the original design.

\section{Disciplines} \\ Engineering | Science and Technology Studies

\section{Publication Details} \\ Huang, S., Ma, Z. \& Wang, F. (2015). A multi-objective design optimization strategy for vertical ground heat \\ exchangers. Energy and Buildings, 87 233-242.
}




\title{
A multi-objective design optimization strategy for vertical ground heat
}

\section{exchangers}

\author{
Su Huang ${ }^{\mathrm{a}}$, Zhenjun $\mathrm{Ma}^{\mathrm{a}, *}$, Fenghao Wang ${ }^{\mathrm{b}}$ \\ ${ }^{\mathrm{a}}$ Sustainable Buildings Research Centre (SBRC), Faculty of Engineering and Information \\ Sciences, University of Wollongong, New South Wales, 2522, Australia \\ ${ }^{\mathrm{b}}$ School of Human Settlements and Civil Engineering, Xi'an Jiaotong University, Xi'an \\ Shanxi Province, 710049, PR China.
}

*Corresponding Author: Phone: 61024221 4143; Email: zhenjun@uow.edu.au

\begin{abstract}
A multi-objective design optimization strategy for vertical U-tube ground heat exchangers (GHEs) is presented to minimize the system upfront cost and entropy generation number simultaneously. Five design variables of vertical U-tube GHEs, including borehole number, borehole depth, borehole radius, U-tube outer radius and fluid mass flow rate, are first selected via a global sensitivity analysis method, and then optimized by a genetic algorithm (GA) optimizer implemented in MATLAB. Based on the Pareto frontier obtained from the GA optimization, a decision-making strategy is then used to determine a final solution. Two case studies are presented to validate the effectiveness of the proposed strategy. The results based on a small scale GSHP system in Australia show that, compared to the original design, the use of this proposed strategy can decrease the total system cost (i.e. the upfront cost and 20 years' operating cost) by 9.5\%. Compared to a single-objective design optimization strategy, $6.2 \%$ more energy can be saved by using this multi-objective design optimization strategy. The result from a relatively large scale GSHP system implemented in China shows that a $5.2 \%$ decrease in the total system cost can be achieved by using this proposed strategy, compared with using the original design.
\end{abstract}

Keywords: Multi-objective optimization; Ground heat exchangers; Entropy generation; Genetic algorithm; Pareto frontier 


\begin{tabular}{|c|c|c|c|}
\hline \multicolumn{4}{|c|}{ Nomenclature } \\
\hline$B$ & borehole distance (m) & $\Delta P$ & pressure drop $(\mathrm{Pa})$ \\
\hline$c$ & specific heat $(\mathrm{J} / \mathrm{kg} \cdot \mathrm{K})$ & $\Delta T$ & temperature difference $(\mathrm{K})$ \\
\hline$C$ & $\operatorname{cost}(\$ / ¥)$ & $\tau$ & time (s) \\
\hline$D$ & half shank space (m) & & \\
\hline$E_{1}(x)$ & exponential integral function & \multicolumn{2}{|c|}{ Subscripts } \\
\hline$f$ & friction number & $b$ & borehole/borehole wall \\
\hline$F_{i j}{ }^{n}$ & non-dimensional objective function & $f$ & fluid \\
\hline$h$ & convective heat transfer coefficient $\left(\mathrm{W} / \mathrm{m}^{2} \cdot \mathrm{K}\right)$ & $G H E$ & ground heat exchanger \\
\hline$k$ & thermal conductivity $(\mathrm{W} / \mathrm{m} \cdot \mathrm{K})$ & $i$ & inner \\
\hline$L$ & length (m) & $H P$ & heat pump \\
\hline $\mathrm{n}$ & number of water-to-water heat pumps & $m$ & mean \\
\hline $\max$ & maximum & $o$ & outer \\
\hline$m_{f}$ & mass flow rate $(\mathrm{kg} / \mathrm{s})$ & $p$ & U-tube pipe \\
\hline $\min$ & minimum & $s$ & soil \\
\hline$N$ & borehole number & tot & total \\
\hline$N_{s}$ & dimensionless entropy generation number & 0 & environmental condition \\
\hline$q$ & heat flux (W/m) & 1 & inlet of the U-tube pipe \\
\hline$Q$ & heat transfer rate $(\mathrm{W})$ & 2 & outlet of the U-tube pipe \\
\hline$r$ & radius (m) & & \\
\hline$R$ & thermal resistance $(\mathrm{m} \cdot \mathrm{K} / \mathrm{W})$ & & \\
\hline$S_{g e n}$ & entropy generation rate $(\mathrm{W} / \mathrm{K})$ & & \\
\hline$T$ & temperature $(\mathrm{K})$ & & \\
\hline$U C$ & upfront cost (\$/¥) & & \\
\hline$\chi$ & dimensionless temperature difference & & \\
\hline$\alpha$ & thermal diffusivity $\left(\mathrm{m}^{2} / \mathrm{s}\right)$ & & \\
\hline$\rho$ & density $\left(\mathrm{kg} / \mathrm{m}^{3}\right)$ & & \\
\hline
\end{tabular}




\section{Introduction}

Enhancing building energy efficiency is crucial nowadays due to the increasing demand on energy supply, and the severity of global warming owing to the greenhouse gas emissions from the use of fossil fuels [1, 2]. Over the past several decades, many different technologies and strategies have been proposed and used to promote building energy efficiency [1-4]. Ground source heat pumps (GSHPs) have been recognized as one of the most sustainable solutions for heating and cooling of buildings due to their year-round high efficiency and environmental friendliness $[4,5]$. GSHPs are gaining market shares with an annual increase rate of $10-30 \%$ in recent years [6]. However, high installation cost, installation infrastructure limitations and system design are still the main challenges preventing the wide adoption of GSHPs in buildings [7].

Over the last several decades, many efforts have been made on the design, modelling and performance evaluation of various GSHP systems. Nagano et al. [8], for instance, developed a design and performance prediction tool for GSHP systems using the infinite cylindrical heat source theory. Capozza et al. [9] proposed a new approach to determining the penalty temperature, an index to evaluate the long-term behavior of the borehole field. Fisher et al. [10] presented the implementation and validation of the ground heat exchanger "g-functions" model in EnergyPlus [11] in order to easily exam the performance of GSHPs in a flexible manner. The thermodynamic performance of GSHP systems was also evaluated using the second law of thermodynamics or exergy analysis $[12,13]$. The exergy analysis performed by Bi et al. [12] showed that the overall exergy efficiency of the GSHP system studied was 0.1 in the heating mode and 0.07 in the cooling mode. Kizikan and Dincer [13] presented an exergy analysis of a borehole thermal storage system for building cooling applications. The results showed that the condenser temperature and evaporator temperature have a strong 
effect on the system exergetic performance and a significant energy saving can be achieved by determining the exergy destructions of all system components.

In most existing design optimization studies for GSHP systems, the minimization of the economic cost or maximization of the thermal performance of the designed system is commonly used as the objective function. The economic cost is usually represented by the concept of net present value, total system cost, etc. Alavy et al. [14] proposed a new methodology for optimization of the capacity of GSHPs in hybrid systems in terms of the net present value. The results indicated that, in most cases, the GSHP systems need to meet more than $80 \%$ of the total design load of hybrid systems. Robert and Gosselin [15] developed a new design method to determine the optimal borehole number, borehole distance, borehole depth, and the optimal size of heat pumps, based on the total cost minimization method. Entropy has also been used to assist in the design optimization of GSHP systems. In the entropy-based optimization, entropy generation number (EGN) is often used as the performance indicator and serves as the objective function in the entropy generation minimization (EGM) method $[16,17]$. A number of studies have used the EGM method in the design optimization of vertical U-tube ground heat exchangers (GHEs). Li and Lai [18], for instance, derived the analytical expressions to determine both the optimal borehole depth and flow velocity by using the EGM method. Huang et al. [19] proposed an EGM based single-objective design optimization method by using genetic algorithms to determine the optimal borehole number, borehole depth, borehole radius, U-tube outer radius and fluid mass flow rate. The above studies were mainly based on the single-objective design optimization. The single-objective design optimization may either increase the system upfront cost if the thermal performance is used as the objective function, or may decrease the system thermodynamic performance if the economic cost is employed as the objective function [20, 21]. 
In order to overcome the disadvantage of single-objective design optimization, multiobjective design optimization has been proposed and used to facilitate the optimal design of various thermodynamic systems. Ndao et al. [21] utilized the thermal resistance and pump power consumption as two objective functions to determine the optimal thermal design and operating conditions of four different shapes of electronic cooling devices. It was concluded that the multi-objective design optimization can provide better performance. Sayyaadi et al. [22] proposed a multi-objective optimization strategy for a vertical U-tube GSHP system to minimize both the total levelized cost and the exergy destruction of the system. Seven temperature differences (e.g. between inlet brine and sub-cooled refrigerant in the condenser, between the outlet air and superheated refrigerant in the evaporator, etc.) and the pipe diameter of the GHE were chosen as the decision variables. The sensitivities of the interest rate, operating hours and the cost of electricity for the optimization were also studied. Gholap and Khan [23] applied a multi-objective optimization procedure by considering energy consumption and material cost as the two different objective functions to optimize the design of heat exchangers for refrigerators. The results demonstrated that this proposed method is technically feasible and effective in the design optimization of the refrigeration equipment with the vapor compression cycle.

From the above studies, it can be found that multi-objective optimization exhibits better performance than that of single-objective optimization. This paper presents a multi-objective design optimization strategy for vertical U-tube ground heat exchangers, in which EGN and system upfront cost are used as two objective functions. The five parameters, including the borehole number, borehole depth, borehole radius, U-tube outer radius and fluid mass flow rate, determined by a global sensitivity analysis are used as the decision variables. Two case studies are presented to validate the effectiveness of the proposed multi-objective design optimization strategy. 


\section{Development and formulation of the design optimization strategy}

\subsection{Outline of the multi-objective design optimization strategy}

Fig. 1 outlines the design optimization strategy for vertical U-tube GHEs proposed in this study, which mainly consists of three steps. The first step is to use a global sensitivity analysis method to reduce the size of the optimization problem by identifying the high sensitive design parameters. The high sensitive design parameters identified will be globally optimized in the second step through a multi-objective genetic algorithm optimizer, to search for a set of Pareto optimal solutions based on the two objective functions defined and the mathematic model of the vertical U-tube heat exchanger as well as the constraints defined for each key design variables. The third step is the decision-making process to determine the desired optimal solution among a set of Pareto optimal points.

Genetic algorithms (GA) with random initialization can provide reasonable good solutions and have been widely applied in engineering and science fields [20, 24]. MATLAB's multi-objective genetic algorithm solver, named as gamultiobj [25], is used in this study to solve the optimization problem and identify a set of Pareto optimal solutions. The gamultiobj genetic algorithm solver consists of the objective functions and the parameter space along with some genetic algorithm options, and the results of the function are a set of non-inferior solutions [25].

The formulation of the objective functions, identification of the key design variables and their constraints, the decision-making in the multi-objective design optimization, and mathematic modelling of vertical U-tube GHEs are described below.

\subsection{Formulation of the objective functions}

There are two different objective functions used to formulate the design optimization strategy. One is the EGN (i.e. entropy generation number) and the other is the system upfront cost. EGN is used to represent the thermodynamic irreversibility due to the friction fluid flow 
and the heat transfer driven by the finite temperature difference in the vertical GHEs [16]. It is represented based on the entropy generation rate $\left(S_{g e n}\right)$ expressed in Equation (1) [16].

$$
N_{s}=\frac{S_{g e n} \cdot T_{f, m}}{Q}
$$

where, $N_{s}$ is the dimensionless entropy generation number, $S_{g e n}$ is the entropy generation rate, $T_{f, m}$ is the mean fluid temperature, and $Q$ is the heat transfer rate.

The system upfront cost $(U C)$ is the sum of the capital costs of major components in the vertical GSHP system, as expressed in Equation (2). As the upfront costs of the water pumps and valves in the pipelines are relatively small when compared to the costs of the water-towater heat pumps and ground heat exchangers, their upfront costs are not considered in this study. The upfront costs of the U-tube ground heat exchangers $\left(U C_{G H E}\right)$ and water-to-water heat pumps $\left(U C_{H P}\right)$ are determined by Equation (3) and Equation (4), respectively.

$$
\begin{gathered}
U C=U C_{G H E}+U C_{H P} \\
U C_{G H E}=C_{p} L_{p}+C_{b} L_{t o t} \\
U C_{H P}=\sum_{i=1}^{n} C_{H P, i}
\end{gathered}
$$

where, $C_{p}$ is the cost of the U-tube per meter, $C_{b}$ is the drilling and grouting costs of per borehole per meter, $C_{H P}$ is the cost of per water-to-water heat pump, $L_{t o t}$ is the total borehole length which is calculated by multiplying the borehole number and borehole depth, $L_{p}$ is the total U-tube length within the boreholes, and $n$ is the total number of the water-to-water heat pumps.

\subsection{Key design variables and constraints}

Usually, three groups of decision variables, including geometry variables, material variables and operational variables, are considered in the design of vertical U-tube GHEs. Based on the global sensitivity analysis using extensive Sobol' method with Monte Carlo 
simulations and parametric studies performed in our previous studies [19, 26], the borehole radius $\left(r_{b}\right)$, fluid mass flow rate per U-tube $\left(m_{f}\right)$, borehole depth $\left(L_{b}\right)$, borehole number $(N)$ and U-tube pipe outer radius $\left(r_{o}\right)$ have been identified as the key decision variables of the vertical U-tube GHEs. It is worthwhile to mention that these five decision variables were determined based on the sensitivity indices in terms of the dimensionless entropy generation number (EGN) as the system upfront cost has a direct relationship with the borehole number $(N)$ and borehole depth $\left(L_{b}\right)$ only, as defined in Equation (3).

These decision variables will be centrally optimized by the genetic algorithm optimization technique based on the constraints defined. The details on the global sensitivity analysis used can be found in Ref. [19].

Defining the constraints of the decision variables is crucial to avoid the infeasible solutions of the optimization problem [27]. In this study, the imposed optimization constraints of the key design variables were determined based on the recommended values from the practical engineering projects $[28,29]$ and are summarized in Table 1 . The acceptable range of the maximal heat flux is chosen between $30 \mathrm{~W} / \mathrm{m}$ and $130 \mathrm{~W} / \mathrm{m}$ [15]. The entering water temperature to the water-to-water heat pumps is considered higher than the ground temperature by $11-17 \mathrm{~K}$ in the cooling mode and is lower than the ground temperature by $6-11 \mathrm{~K}$ in the heating mode [28]. The values of the other variables used in this study are summarized in Table 2, which are the recommended values from the practical engineering projects as well $[28,29]$.

2.4 Decision-making in the multi-objective design optimization

Multi-objective optimization problems usually exhibit a probably uncountable set of solutions to assess the status of vectors showing the best possible trade-offs in the objective function space [20-22]. The Pareto frontier is one of the key concepts and can be used to 
establish a hierarchy among the solutions of a multi-objective optimization problem, in order to determine whether a solution is one of the best possible trades-offs [20-22].

In multi-objective design optimization, the decision-making is essential for the selection of the final solution among a set of optimum points on the Pareto frontier. The decisionmaking process is generally performed based on the engineering experience and the importance of each objective for decision-makers [20, 22]. In this study, a hypothetical point, named as ideal point, is used to assist in determining the final optimal solution in the decision-making process [30]. In the Pareto frontier, both objectives have their optimum values and are independent with each other in the ideal point. The ideal point cannot be located on the Pareto frontier as it is impossible to have both objectives at their optimum values simultaneously. Therefore, the closest point of the Pareto frontier to the ideal point can be considered as a desired final solution [31]. The dimension of various objectives in a multiobjective optimization problem might be different. For instance, in this study, the EGN is a dimensionless objective while the system upfront cost is a dimensional objective. It is therefore necessary to non-dimensionalize the objective vectors before the decision-making process [30, 32].

In this study, the solutions on the Pareto frontier are normalized using a fuzzy nondimensionalization method, in which the non-dimensional objective function $\left(F_{i j}{ }^{n}\right)$, is defined by Equation (5) for minimizing objectives or Equation (6) for maximizing objectives [32].

$$
\begin{aligned}
& \min F_{i j}^{n}=\frac{\max \left(F_{i j}\right)-F_{i j}}{\max \left(F_{i j}\right)-\min \left(F_{i j}\right)} \\
& \max F_{i j}^{n}=\frac{F_{i j}-\min \left(F_{i j}\right)}{\max \left(F_{i j}\right)-\min \left(F_{i j}\right)}
\end{aligned}
$$

where $i j$ is an index for each individual solution on the Pareto frontier, min and max represent the minimum and maximum values of each objective among the corresponding values for all 
solutions on the Pareto frontier. The normalized values for each objective vary between 0 and 1.

2.5 Mathematical modelling of vertical U-tube ground heat exchangers

The heat transfer, pressure drop and entropy generation calculations of vertical U-tube GHEs are briefly described below. More details can be found in Ref. [19].

The infinite line source model (LSM) developed based on Kelvin's line source theory [6], is used to analyze the heat transfer of GHEs. In the vicinity of the borehole, for sufficiently long time scales and constant heat flux, the line source model gives the expression below to determine the borehole wall temperature $\left(T_{b}\right)$. This model can provide acceptable prediction when the simulation time $(\tau)$ is larger than $20 r_{b}{ }^{2} / a_{s}[6,33]$.

$$
T_{b}=T_{s}\left(r_{b}, \tau\right)=T_{s, 0}+\frac{q}{4 \pi k_{s}} \int_{\frac{r_{b}^{2}}{4 \alpha_{s} \tau}}^{\infty} \frac{e^{-u}}{u} d u \cong T_{s, 0}+\frac{q}{4 \pi k_{s}} E_{1}\left(\frac{r_{b}^{2} \rho_{s} c_{s}}{4 k_{s} \tau}\right)
$$

where, $T_{s, 0}$ is the undisturbed soil temperature, $r_{b}$ is the borehole radius, $q$ is the heat flux determined by Equation (8), $k_{s}$ is the soil thermal conductivity, $\alpha_{s}$ is the thermal diffusivity, $\tau$ is the simulation time, $E_{1}(x)$ is the exponential integral function, $\rho_{s}$ is the soil density, and $c_{s}$ is the specific heat of the soil.

$$
q=\frac{Q}{N L_{b}}
$$

where, $N$ is the borehole number, and $L_{b}$ is the borehole depth.

The borehole thermal resistance $\left(R_{b}\right)$ driven by the line-source approximation is determined by Equation (9), in which the pipe thermal resistance $\left(R_{p}\right)$ is calculated by Equation $(10)[18,34]$. The pressure drop $(\Delta P)$ along a single U-tube pipe is determined by Equation (11) [18].

$$
R_{b}=\frac{1}{4 \pi k_{b}}\left[\ln \frac{r_{b}}{r_{o}}+\ln \frac{r_{b}}{2 D}+\frac{k_{b}-k_{s}}{k_{b}+k_{s}} \ln \left(\frac{r_{b}^{4}}{r_{b}^{4}-D^{4}}\right)\right]+\frac{R_{p}}{2}
$$




$$
\begin{gathered}
R_{p}=\frac{1}{2 \pi k_{p}} \ln \frac{r_{o}}{r_{i}}+\frac{1}{2 \pi r_{i} h_{f}} \\
\Delta P=f \frac{m_{f}^{2}\left(2 L_{b}\right)}{\rho_{f} \pi^{2} r_{i}^{5}}
\end{gathered}
$$

where, $r_{i}$ and $r_{o}$ are the inner radius and outer radius of the U-tube respectively, $D$ is the half shank space, $h_{f}$ is the convective heat transfer coefficient, $k_{b}$ is the thermal conductivity of the grout material, $k_{p}$ is the thermal conductivity of the U-tube, $f$ is the friction factor, $m_{f}$ is the mass flow rate per U-tube pipe, and $\rho$ is the fluid density.

Entropy generation is a term used to evaluate the thermodynamic irreversibility losses of a heat exchanger. The total entropy generation rate $\left(S_{g e n}\right)$ in vertical U-tube GHEs can be considered as the sum of the entropy generation rate caused by the finite temperature difference $\left(S_{g e n, \Delta T}\right)$ and the entropy generation rate caused by the fluid friction $\left(S_{g e n, \Delta P}\right)[16]$.

$$
S_{g e n}=S_{g e n, \Delta T}+S_{g e n, \Delta P}=\frac{Q \Delta T}{T_{f, m}^{2}(1+\chi)}+\frac{m_{f, t o t} \Delta P}{\rho_{f} T_{f, m}}
$$

where, $\chi$ is a dimensionless temperature difference defined as $\chi=\Delta T / T_{f, m}$, which can be negligible on the thermodynamic temperature scale [16], $T_{f, m}$ is the mean temperature of the fluid defined as $T_{f, m}=\left(T_{f, 1}-T_{f, 2}\right) / \ln \left(T_{f, 1} / T_{f, 2}\right)$ and can be regarded as a convenient representative mean fluid bulk temperature in the pipe, and $\Delta T$ is the temperature difference between the mean temperature of the fluid $\left(T_{f, m}\right)$ and the borehole wall temperature $\left(T_{b}\right)$ [16], and $m_{f, t o t}$ is the total mass flow rate of the system.

\section{Performance tests and evaluation}

\subsection{Description of two case studies}

In this study, two case studies are used to validate the effectiveness of the proposed multiobjective design optimization strategy for vertical U-tube GHEs. Case I is based on a small scale GSHP implemented in the Sustainable Buildings Research Centre (SBRC) at University 
of Wollongong, Australia. Wollongong is in the Australian Climate Zone 5 with a mild, oceanic climate. Fig 2a) illustrates the render of the building. In this GSHP system, two water-to-water heat pumps connected with three vertical U-tube ground heat exchangers and a total of twelve horizontal linear heat exchangers are used to supply around $20 \%$ of the total heating and cooling demand of the building while the rest heating and cooling demand of the building is supplied by an air-source heat pump. For simplification of the optimization process, the three vertical U-tube ground heat exchangers connected with one water-to-waterheat pump are considered in this study.

Case II is based on a relatively large scale GSHP system designed for a three story dining hall, as illustrated in Fig. 2b), at Xi'an Jiaotong University, China. Xi'an is in the sub-humid warm temperate continental monsoon climate with hot and humid summer, cold and dry winter. The total floor area of the building is $15,528 \mathrm{~m}^{2}$, and the total design cooling load and heating load of the building are $1871 \mathrm{~kW}$ and $1451 \mathrm{~kW}$, respectively. The GSHP system in this building consists of 270 vertical U-tube GHEs with a $100 \mathrm{~m}$ borehole depth each, a 90 $\mathrm{mm}$ borehole radius and a $4 \mathrm{~m}$ borehole distance. The total required installation area is 4320 $\mathrm{m}^{2}$. In order to simplify the simulation process, a water-to-water heat pump with a cooling capacity of $937 \mathrm{~kW}$ is assumed to connect with the 270 vertical boreholes to supply the heating and cooling for the cooking area and student dining area, which accounts for approximately $50 \%$ of the total building heating and cooling demand. The rest heating and cooling demand of the building is supplied by the conventional air-conditioning systems.

The specifications and design conditions of the above two GSHP systems are summarized in Table 2. The indicative installation costs for vertical U-tube GHEs in Australia and in China are presented in Table 3. 


\subsection{Setup of the tests}

A simulation platform, illustrated in Fig. 3, which was developed based on TRNSYS [35], is used to facilitate the system performance evaluation and economic analysis. In this simulation platform, the major component models used were the mathematical models provided in the standard TRNSYS library. The key component models used are the water-towater heat pump model (Type 927), vertical U-tube GHE model (Type 557), and water pump model (Type 110).

Fig. 4a) illustrates the total heating and cooling loads of the SBRC building (Case I) studied, which were simulated by using DesignBuilder [36], based on the RMY weather data for Sydney (Australia) as shown in Fig. 4b). The positive value in the figure indicates the cooling load while the negative value represents the heating load. In the simulation, the load allocation for the three vertical U-tube ground heat exchangers with one water-to-water heat pump concerned was based on the heating/cooling capacity of the water-to-water heat pump and the operation priority given to the GSHP with the three vertical U-tube ground heat exchangers. Fig. 5a) shows the total heating and cooling loads of the three story dining hall (Case II) with the floor areas supplied by the GSHP system, based on the Chinese Standard Weather Data (CSWD) for Xi'an, China, as shown in Fig. 5b), which was also simulated using DesignBuilder [36].

\subsection{Test results from Case I}

\subsubsection{Determination of the final optimal solution in the multi-objective design optimization}

Fig. 6 presents the Pareto optimum frontier obtained by using the proposed multiobjective design optimization strategy, which was generated based on the design conditions described in Table 2 and the cost data presented in Table 3. It can be found that the system upfront cost decreased with the increase of the EGN, which indicates that the optimal solutions are the trade-off between the two competing objective functions. Theoretically, 
each point on the Pareto frontier could be the optimal solution for a specific project dependent on the preference of the decision makers and the project limits.

Fig. 7 shows the approach employed to determining the final optimal solution, and the normalized Pareto frontier based on the method introduced in Section 2.4. The closest point in the normalized Pareto frontier to the ideal unreachable point (e.g. hypothetical point) was selected as the desired final optimal solution. This solution is considered as a trade-off between the system upfront cost and EGN. It is worthy to note that the final solution determined by this approach might not be the globally optimized solution but it can be considered as one of the best candidate solutions.

\subsubsection{Comparison among the results using different design strategies}

In this section, a comparison among the results by using the proposed multi-objective design optimization strategy and an entropy generation minimization (EGM)-based singleobjective design optimization strategy as well as the original design is provided. The EGMbased single-objective design optimization strategy employed the EGN as the objective function, and used the same mathematic models and optimization constraints as that used in the proposed multi-objective design optimization strategy. The details on the EGM singleobjective design optimization strategy used can be found in Ref. [19].

Table 4 summaries the results obtained by using the three different design strategies. It can be observed that the EGNs by using the original design, EGM-based single-objective design optimization and multi-objective design optimization were 0.2180, 0.1913 and 0.1929, respectively. The higher EGN represents the larger thermal irreversibility and the lower thermal performance of the vertical U-tube GHEs. Compared to the original design, a $12.2 \%$ reduction in the EGN was achieved by using the EGM-based single-objective design optimization, and an $11.5 \%$ reduction was achieved by using the proposed multi-objective design optimization. Compared with the EGM-based single-objective design optimization, 
the use of the multi-objective design optimization resulted in a larger EGN. The larger EGN may deteriorate the thermal performance of the vertical U-tube GHEs, but it will help reduce the system upfront cost, which will be demonstrated in Section 3.3.3.

\subsubsection{Economic analysis}

An economic analysis was also performed to validate the effectiveness of the proposed multi-objective design optimization strategy for the vertical U-tube GHEs. In this study, the total system cost, including the upfront cost and 20 years' operating cost of the concerned GSHP system, is used as the performance indicator. The analysis was performed based on the simulation platform presented in Fig. 3 and the cost data presented in Table 3.

The annual maximum entering water temperature to the water-to-water heat pump and the variation of the annual energy consumption of the GSHP system with the vertical U-tube GHEs in 20 years of operation are shown in Fig. 8 and Fig. 9, respectively. As mentioned earlier, the energy consumption of the water pump in the system was not included although including energy consumption of the water pump will affect the overall optimization results, but the impact on the total system cost will be around $1.0 \%$ for this case. It is worthwhile to mention that inappropriate design of the ground loop system and improper selection of circulating water pumps may severely impair the overall efficiency of GSHP systems. It is shown that the annual maximum entering water temperature to the water-to-water heat pump and the annual energy consumption of the concerned system by using the proposed multiobjective design optimization strategy were higher than that using the EGM-based singleobjective design optimization and the original design. This is mainly due to the reduction of the total borehole length when the proposed strategy was used. The less total borehole length resulted in an increase in the heat flux per meter per borehole, which increased the mean circulating fluid temperature in the vertical U-tube GHEs. The increase of the entering water temperature will lead to an increase of the energy consumption of the water-to-water heat 
pump for this cooling-dominated building. Compared to the original design and the EGMbased single-objective design optimization, the use of the proposed strategy can result in a reduction of the total borehole length by $19.4 \%$ and $12.7 \%$, respectively. The use of the EGM-based single-objective design optimization also led to a higher annual energy consumption and a larger annual maximum entering water temperature to the water-to-water heat pump, as compared to the original design. From Fig. 9, it can also be found that the annual energy consumption of the GSHP system increased with the increase of the operating years due to the performance degradation of the vertical U-tube GHEs resulted by the unbalanced heat rejection and extraction.

Table 5 summarizes the results from the economic analysis by using the three different designs. It is clearly shown that the total system costs (i.e. the upfront cost and 20 years' operating cost) by using the proposed multi-objective design optimization and EGM-based single-objective design optimization were $9.5 \%$ and $3.5 \%$ lower than that by using the original design, respectively. However, the system operating costs by using the multiobjective design optimization and EGM-based single-objective design optimization were $\$ 15,181$ and $\$ 15,058$ respectively, where were $2.7 \%$ and $1.9 \%$ higher than that of using the original design, while the system upfront costs by using the two design optimization strategies were $\$ 25,360$ and $\$ 28,176$, respectively, where were $15.5 \%$ and $6.2 \%$ lower than that using the original design.

The above results demonstrated that the optimal solution determined based on the tradeoff between the system upfront cost and EGN by using the proposed design strategy is more cost effective and economic viable. 


\subsection{Test results from Case II}

\subsubsection{Determination of the final optimal solution in the multi-objective design optimization}

Fig. 10 shows the desired optimal point and normalized Pareto frontier of the two objective functions, which was determined based on the cost data in China presented in Table 3. The normalization of the original Pareto frontier was carried out using the same method as that used in Case I.

The optimal values of the decision variables obtained by using the proposed multiobjective design optimization strategy are compared with that of the original design and are summarized in Table 6. The optimized borehole number and the total area required for installation of the vertical U-tube GHEs by using the proposed strategy were 164 and 2624 $\mathrm{m}^{2}$, respectively. Compare to the original design which required a land area of $4320 \mathrm{~m}^{2}$, a 39.3\% reduction in the installation area was achieved by using the proposed design optimization strategy when the same borehole distance of $4 \mathrm{~m}$ was used. The shortage of available land source is always a common problem in metropolises. The minimization of the usage of the land area for installation of vertical U-tube GHEs is therefore important. The results also show that the EGNs of using the original design and multi-objective design optimization were 0.2125 and 0.1885 , respectively. Compared to the original design, around 11.3\% decrease in the EGN was achieved by using the multi-objective design optimization strategy.

\subsubsection{Economic analysis}

An economic analysis was also performed for validating the effectiveness of the multiobjective design optimization strategy for this case. Fig. 11 and Fig. 12 illustrate the annual maximum entering water temperature to the water-to-water heat pumps and annual energy consumption of the GSHP system under the two different designs, respectively. Similar conclusions as that from Case I can be drawn that the annual maximum entering water 
temperature to the water-to-water heat pumps using the multi-objective design optimization strategy was larger than that using the original design.

Table 7 summarizes the results from the economic analysis by using the original design and the multi-objective design optimization. It is clearly shown that the total system cost (i.e. the upfront cost and 20 years' operating cost) by using the multi-objective design optimization strategy was $¥ 9,371,595$, which was $5.2 \%$ lower than that of using the original design. The 20 years' operating cost of the system by using the multi-objective design optimization strategy was $¥ 5,807,755$, which was $3.1 \%$ higher than that of using the original design, while the system upfront cost using the multi-objective design optimization was $¥ 3,563,840$, where was $16.3 \%$ lower than that of the original design.

\section{Conclusion}

This paper presented a multi-objective design optimization strategy for vertical U-tube ground heat exchangers used in GSHP systems. A multi-objective genetic algorithm implemented in MATLAB was used to search for a set of Pareto optimal solutions, which were presented in the Pareto frontier. A decision-making strategy based on an ideal point was used to determine a final optimal solution.

The performance of the proposed multi-objective design optimization strategy was validated based on a small scale GSHP system in Australia (Case I) and a relatively large scale GSHP system in China (Case II), respectively. The results from Case I showed that the use of the proposed strategy can achieve around 9.5\% total system cost savings (i.e. the upfront cost and 20 years' operating cost) of the GSHP system concerned, as compared to the use of the original design. Compared to the single-objective design optimization with the entropy generation number (EGN) as the objective function, 6.2\% more energy can be saved by using the multi-objective design optimization, based on the same mathematic models and optimization constraints. The results from Case II showed that the use of the multi-objective 
design optimization can result in a 5.2\% reduction in the total system cost, when compared with that of using the original design. The results from both case studies also demonstrated that the proposed multi-objective design optimization strategy taking into consideration of both thermodynamic and economical aspects is technically feasible and effective in facilitating the design of vertical U-tube ground heat exchangers.

\section{Acknowledgement}

The authors would like to thank Professor Paul Cooper for his continuous support and encouragement for conducting this research work, and Mr Yale Carden, Managing Director of GeoExchange Australia Pty Ltd for providing the cost data for the installation of ground source heat pump systems in Australia. The authors also thank Miss Tian Wang from the School of Human Settlements and Civil Engineering, Xi'an Jiaotong University for valuable discussions on the building and system presented in Case II.

\section{References}

[1] G. Heravi, M. Qaemi, Energy performance of buildings: The evaluation of design and construction measures concerning building energy efficiency in Iran, Energy and Building 75 (2014) 456-464.

[2] T.A.H. Ratlamwala, I. Dincer, Development of a geothermal based integrated system for building multigenerational needs, Energy and Buildings 62 (2013) 496-506.

[3] Z.J. Ma, S.W. Wang, Enhancing the performance of large primary-secondary chilled water systems by using bypass check valve, Energy 36 (2011) 268-76.

[4] N. Zhu, P. Hu, L. Xu, Z. Jiang, F. Lei, Recent research and applications of ground source heat pump integrated with thermal energy storage systems: A review, Applied Thermal Engineering 71 (2014) 142-151. 
[5] F.M. Rad, A.S. Fung, W.H. Leong, Feasibility of combined solar thermal and ground source heat pump systems in cold climate Canada, Energy and Buildings 61 (2013) 224232.

[6] H. Yang, P. Cui, Z.H. Fang, Vertical borehole ground source heat pumps: A review of models and systems, Applied Energy 87 (2010) 16-27.

[7] W. Goetzler, M. Guernsey, R. Kar, Research and development roadmap: Geothermal (ground-source) heat pumps, U.S. Department of Energy, Energy Efficiency and Renewable Energy, October 2012.

[8] K. Nagano, T. Katsura, S. Takeda, Development of a design and performance prediction tool for the ground source heat pump system, Applied Thermal Engineering 26 (2006) 1578-1592.

[9] A. Capozza, M.D. Carli, A. Zarrella, Design of borehole heat exchangers for groundsource heat pumps: A literature review, methodology comparison and analysis on the penalty temperature, Energy and Buildings 55 (2012) 369-379.

[10]D.E. Fisher, S.J. Rees, S.K. Padhmanabhan, A. Murugappan, Implementation and validation of ground-source heat pump system models in an integrated building and system simulation environment, HVAC\&R Research 12 (2006) 693-710.

[11]D.B. Crawley, L.K. Lawrie, F.C. Winkelmann, W. Buhl, Y.J. Huang, C.O. Pedersen, R.K. Strand, R.J. Liesen, D.E. Fisher, M.J. Witte, J. Glazer, EnergyPlus: Creating a newgeneration building energy simulation program, Energy and Buildings 33 (2001) 319331.

[12]Y.H. Bi, X.H. Wang, Y. Liu, H. Zhang, L.G. Chen, Comprehensive exergy analysis of a ground-source heat pump system for both building heating and cooling modes, Applied Energy 86 (2009) 2560-2565. 
[13]O. Kizilkan, I. Dincer, Exergy analysis of borehole thermal energy storage system for building cooling applications, Energy and Buildings 49 (2012) 568-574.

[14]M. Alavy, V. Nguyen Hiep, H.W. Leong, B, Dworkin Seth, A methodology and computerized approach for optimizing hybrid ground source heat pump system design, Renewable Energy 57 (2013) 404-412.

[15] F. Robert, L. Gosselin, New methodology to design ground coupled heat pump systems based on total cost minimization, Applied Thermal Engineering 62 (2) (2014) 481-491.

[16]A. Bejan, Entropy generation minimization: the method of thermodynamic optimization of finite-size systems and finite-time processes, Boca Raton: CRC Press Inc., 1996.

[17] P. Maheshkumar, C. Muraleedharan, Minimization of entropy generation in flat heat pipe, International Journal of Heat Mass Transfer 54 (1-3) (2011) 645-248.

[18]M. Li, A.K.C. Lai, Thermodynamic optimization of ground heat exchangers with single U-tube by entropy generation minimization method, Energy Conversation and Management 65 (2013) 133-139.

[19]S. Huang, Z.J. Ma, P. Cooper, Optimal design of vertical ground heat exchangers by using entropy generation minimization method and genetic algorithms, Energy Conversion and Management 87 (2014) 128-137.

[20]H. Najafi, B. Najafi, P. Hoseinpoori, Energy and cost optimization of a plate and fin heat exchanger using genetic algorithm, Applied Thermal Engineering 31 (2011) 1839-1847.

[21]S. Ndao, Y. Peles, M.K. Jensen, Multi-objective thermal design optimization and comparative analysis of electronic cooling technologies, International Journal of Heat Mass Transfer 52 (2009) 4317-4326.

[22] H. Sayyaadi, E. Hadaddi, M. Amidpour, Multi-objective optimization of a vertical ground source heat pump using evolutionary algorithm, Energy Conversion and Management 50 (2009) 2035-2046. 
[23] A.K. Gholap, J.A. Khan, Design and multi objective optimization of heat exchangers for refrigerators, Applied Energy 84 (2007) 1226-1239.

[24] Z.J. Ma, S.W. Wang, Testing and evaluation of energy saving potentials in a complex building central chilling system using genetic algorithm, Building Services and Engineering Research and Technology 32 (2011) 109-126.

[25]Genetic Algorithm and Direct Search Toolbox for use with MATLAB, User's Guide, Version 1, Release 13SP1+, The Mathworks Inc., 2004.

[26]S. Huang, Z.J. Ma, P. Cooper, Evaluation of a ground source heat pump system in a netzero energy office building, In: 12th International Conference on Sustainable Energy Technologies, Hong Kong, (2013) 1-9.

[27]B. Chachuata, B. Srinivasanb, D. Bonvin, Model parameterization tailored to real-time optimization, Computer and Chemical Engineering 25 (2008) 1-13.

[28]ASHRAE, HVAC applications. SI Edition., 2011.

[29]D. Banks, An introduction to thermogeology: ground source heating and cooling (2nd ed), John Wiley \& Sons, Inc., 2012.

[30]M. Navidbakhsh, A. Shirazi, S. Sanaye, Four E analysis and multi-objective optimization of an ice storage system incorporating PCM as the partial cold storage for airconditioning applications, Applied Thermal Engineering 58 (2013) 30-41.

[31] M.M. Ghanadi Arab, M. Hajabdollahi, H. Hajabdollahi, Multi-objective optimization of a fin with two-dimensional heat transfer using NSGA-II and ANN, Journal of Applied Mechanic Engineering 2 (2) (2013) 1-7.

[32]M.H. Ahmadi, H. Hosseinzade, H. Sayyaadi, A.H. Mohammadi, F. Kimiaghalam, Application of the multi-objective optimization method for designing a powered Stirling heat engine: design with maximized power, thermal efficiency and minimized pressure loss, Renewable Energy 60 (2013) 313-322. 
[33]M. He, Numerical modelling of geothermal borehole heat exchanger systems, Doctoral Thesis, De Montfort University, UK, 2012.

[34]L. Lamarche, S. Kajl, B. Beauchamp, A review of methods to evaluate borehole thermal resistances in geothermal heat-pump systems, Geothermics 39 (2010) 187-200.

[35]S. A. Klein, A Transient System Simulation Program (TRNSYS 17) Manual. Thermal Energy System Specialists. Madison, USA, (2010).

[36]A. Tindale, Designbuilder and energyplus, The Building Energy Simulation User News 25 (2004) 2-5. 


\section{Tables}

Table 1 Ranges of the design variables of vertical U-tube heat exchangers [28, 29]

\begin{tabular}{c|l|c}
\hline \multicolumn{1}{|c|}{ Design parameters } & Values or ranges \\
\hline \multirow{2}{*}{ Geometry } & Number of boreholes $N$ & {$\left[1, \frac{Q_{t o t}}{q_{\text {min }} L_{b, \text { min }}}\right]$} \\
parameters & Borehole depth $L_{b}(\mathrm{~m})$ & {$[50,200]$} \\
& Borehole distance $B(\mathrm{~m})$ & {$[3,10]$} \\
& Borehole radius $r_{b}(\mathrm{~m})$ & {$[0.0325,0.1]$} \\
& Pipe outer radius $r_{o}(\mathrm{~m})$ & {$[0.012,0.022]$} \\
& Half shank space D $(\mathrm{m})$ & {$\left[0, \mathrm{r}_{\mathrm{b}}-2 \mathrm{r}_{\mathrm{o}}\right]$} \\
\hline \multirow{2}{*}{ Material } & Pipe material conductivity $k_{p}(\mathrm{~W} / \mathrm{m} \cdot \mathrm{K})$ & {$[0.2,0.6]$} \\
parameters & Grout material conductivity $k_{b}(\mathrm{~W} / \mathrm{m} \cdot \mathrm{K})$ & {$[0.5,2.5]$} \\
& Soil material conductivity $k_{s}(\mathrm{~W} / \mathrm{m} \cdot \mathrm{K})$ & {$[0.5,2.5]$} \\
\hline \multirow{2}{*}{ Operating } & Circulating fluid mass flow rate per pipe $m_{f}(\mathrm{~kg} / \mathrm{s})$ & {$[0.1,1]$} \\
conditions & Undisturbed soil temperature $T_{s, 0}\left({ }^{\circ} \mathrm{C}\right)$ & {$[10,20]$} \\
\hline
\end{tabular}

Table 2 Design specifications and design conditions of the two GSHP systems concerned

\begin{tabular}{|c|c|c|c|}
\hline & Parameters & Case I & Case II \\
\hline Pipe material & nductivity $k_{p}(\mathrm{~W} / \mathrm{m} \cdot \mathrm{K})$ & 0.5 & 0.5 \\
\hline Borehole dis & $B(\mathrm{~m})$ & 8 & 4 \\
\hline Half shank s] & $D(\mathrm{~m})$ & $r_{b}-2 r_{o}$ & $r_{b}-2 r_{o}$ \\
\hline Soil material & iductivity $k_{s}(\mathrm{~W} / \mathrm{m} \cdot \mathrm{K})$ & 2.0 & 2.0 \\
\hline Grout materi & nermal conductivity $k_{b}(\mathrm{~W} / \mathrm{m} \cdot \mathrm{K})$ & 2.42 & 2.42 \\
\hline Undisturbed & temperature $T_{s, 0}\left({ }^{\circ} \mathrm{C}\right)$ & 20 & 18 \\
\hline & Design cooling load (kW) & 15 & 927 \\
\hline Design & Indoor design temperature $\left({ }^{\circ} \mathrm{C}\right)$ & 24 & 25 \\
\hline condition & Outdoor design temperature $\left({ }^{\circ} \mathrm{C}\right)$ & 31 & 33 \\
\hline & Mean undisturbed soil temperature $\left({ }^{\circ} \mathrm{C}\right)$ & 20 & 18 \\
\hline Water-to- & Rated cooling capacity/power (kW/kW) & $16.4 / 4.1$ & $937 / 209$ \\
\hline pump & Rated heating capacity/power (kW/kW) & $20.5 / 5.5$ & $1024 / 231$ \\
\hline
\end{tabular}


Table 3 Installation costs for vertical U-tube heat exchangers

\begin{tabular}{|c|c|c|}
\hline Component & Cost (Australia) & Cost (China) \\
\hline U-shaped polyethylene pipe & $2.5^{*} \quad(\$ / m)$ & $10(¥ / \mathrm{m})$ \\
\hline Drilling cost & $(\$ / m)$ & \multirow{2}{*}{$110(¥ / \mathrm{m})$} \\
\hline Grouting cost & $(\$ / \mathrm{m})$ & \\
\hline Water-to-water heat pump & 6000 (\$/unit) & 749,600 (¥/unit) \\
\hline Electricity price & $0.25(\$ / \mathrm{kWh})$ & $0.79(¥ / \mathrm{kWh})$ \\
\hline
\end{tabular}

* Mean cost determined based on the installation costs for $40 \mathrm{~mm}$ and $32 \mathrm{~mm}$ outer diameters of the Ushaped polyethylene pipes

Table 4 Comparison among three different designs - Case I

\begin{tabular}{l|c|c|c|c|c|c|c}
\hline Design optimization strategy & $\begin{array}{c}r_{b} \\
(\mathrm{~m})\end{array}$ & $\begin{array}{c}m_{f} \\
(\mathrm{~kg} / \mathrm{s})\end{array}$ & $\begin{array}{c}L_{b} \\
(\mathrm{~m})\end{array}$ & $\begin{array}{c}N \\
(-)\end{array}$ & $\begin{array}{c}r_{o} \\
(\mathrm{~m})\end{array}$ & $\begin{array}{c}\text { EGN } \\
(-)\end{array}$ & $\begin{array}{c}\text { EGN } \\
\text { reduction } \\
(\%)\end{array}$ \\
\hline Original & 0.075 & 0.4 & 91 & 3 & 0.020 & 0.2180 & - \\
\hline EGM-based single-objective & 0.06 & 0.595 & 126 & 2 & 0.016 & 0.1913 & 12.2 \\
\hline Multi-objective & 0.085 & 0.75 & 110 & 2 & 0.020 & 0.1929 & 11.5 \\
\hline
\end{tabular}

Table 5 Economic analysis of the system by using three different designs - Case I

\begin{tabular}{l|c|c|c}
\hline & $\begin{array}{c}\text { Original } \\
\text { design }\end{array}$ & $\begin{array}{c}\text { Single-objective } \\
\text { design }\end{array}$ & $\begin{array}{c}\text { Multi-objective } \\
\text { design }\end{array}$ \\
\hline Number of boreholes & 3 & 2 & 2 \\
\hline Borehole depth (m) & 91 & 126 & 110 \\
\hline $\begin{array}{l}\text { Energy consumption in 20 years’ } \\
\text { operation (kWh) }\end{array}$ & $59,127.7$ & $60,232.7$ & $60,723.8$ \\
\hline 20 years’ operating cost (\$) & $14,781.9$ & $15,058.2$ & $15,180.9$ \\
\hline Total upfront cost (\$) & $30,024.0$ & $28,176.0$ & $25,360.0$ \\
\hline $\begin{array}{l}\text { Total system cost (i.e. upfront cost } \\
\text { and 20 years’ operating cost) }(\$)\end{array}$ & $44,805.9$ & $43,234.2$ & $40,540.9$ \\
\hline Total cost savings (\%) & - & 3.5 & 9.5 \\
\hline
\end{tabular}


Table 6 Comparison between the two different designs - Case II

\begin{tabular}{|c|c|c|c|c|c|c|c|c|}
\hline $\begin{array}{l}\text { Design } \\
\text { optimization } \\
\text { strategy }\end{array}$ & $\begin{array}{c}r_{b} \\
(\mathrm{~m})\end{array}$ & $\begin{array}{c}m_{f} \\
(\mathrm{~kg} / \mathrm{s})\end{array}$ & $\begin{array}{c}L_{b} \\
(\mathrm{~m})\end{array}$ & $N$ & $\begin{array}{c}r_{o} \\
(\mathrm{~m})\end{array}$ & $\begin{array}{c}\text { Installation } \\
\text { area } \\
\left(\mathrm{m}^{2}\right)\end{array}$ & EGN & $\begin{array}{c}\text { EGN } \\
\text { reduction } \\
(\%)\end{array}$ \\
\hline Original & & 0 & 20 & 27 & 0.0 & 4320 & & - \\
\hline Multi-objective & 0.095 & 0.55 & 132 & 164 & 0.022 & $2624^{*}$ & 0.1885 & 11.3 \\
\hline
\end{tabular}

* The installation area was estimated based on the assumption of the squared configuration of the boreholes.

Table 7 Economic cost analysis of the system by using two different design strategies - Case

\section{II}

\begin{tabular}{l|c|c}
\hline & Original design & Multi-objective design \\
\hline Number of boreholes & 270 & 164 \\
\hline Borehole depth (m) & 100 & 132 \\
\hline $\begin{array}{l}\text { Energy consumption in 20 years’ operation } \\
(\mathrm{kWh})\end{array}$ & $7,128,020$ & $7,351,588$ \\
\hline 20 years’ operating cost (¥) & $5,631,136$ & $5,807,755$ \\
\hline Total system upfront cost (¥) & $4,259,600$ & $3,563,840$ \\
\hline $\begin{array}{l}\text { Total system cost (i.e. upfront cost and 20 } \\
\text { years’ operating cost) (¥) }\end{array}$ & $9,890,736$ & $9,371,595$ \\
\hline Total cost savings (\%) & - & 5.2 \\
\hline
\end{tabular}




\section{Figure Captions}

Fig. 1 Outline of the design optimization strategy

Fig. 2 Renders of the buildings concerned in this study

Fig. 3 Simulation platform developed by TRNSYS

Fig.4 Building heating and cooling load profiles and weather conditions - Case I

Fig.5 Load profiles of the areas conditioned by GSHP and weather conditions - Case II

Fig. 6 Illustration of the Pareto optimal frontier identified - Case I

Fig. 7 Normalized Pareto frontier and determination of the final solution - Case I

Fig. 8 Annual maximum entering water temperature to the water-to-water heat pump - Case I

Fig. 9 Annual energy consumption of the GSHP concerned - Case I

Fig. 10 Normalized Pareto frontier and determination of the final solution - Case II

Fig. 11 Annual maximum entering water temperature to the water-to-water heat pumps Case II

Fig. 12 Annual energy consumption of the GSHP concerned - Case II 


\section{Figures}

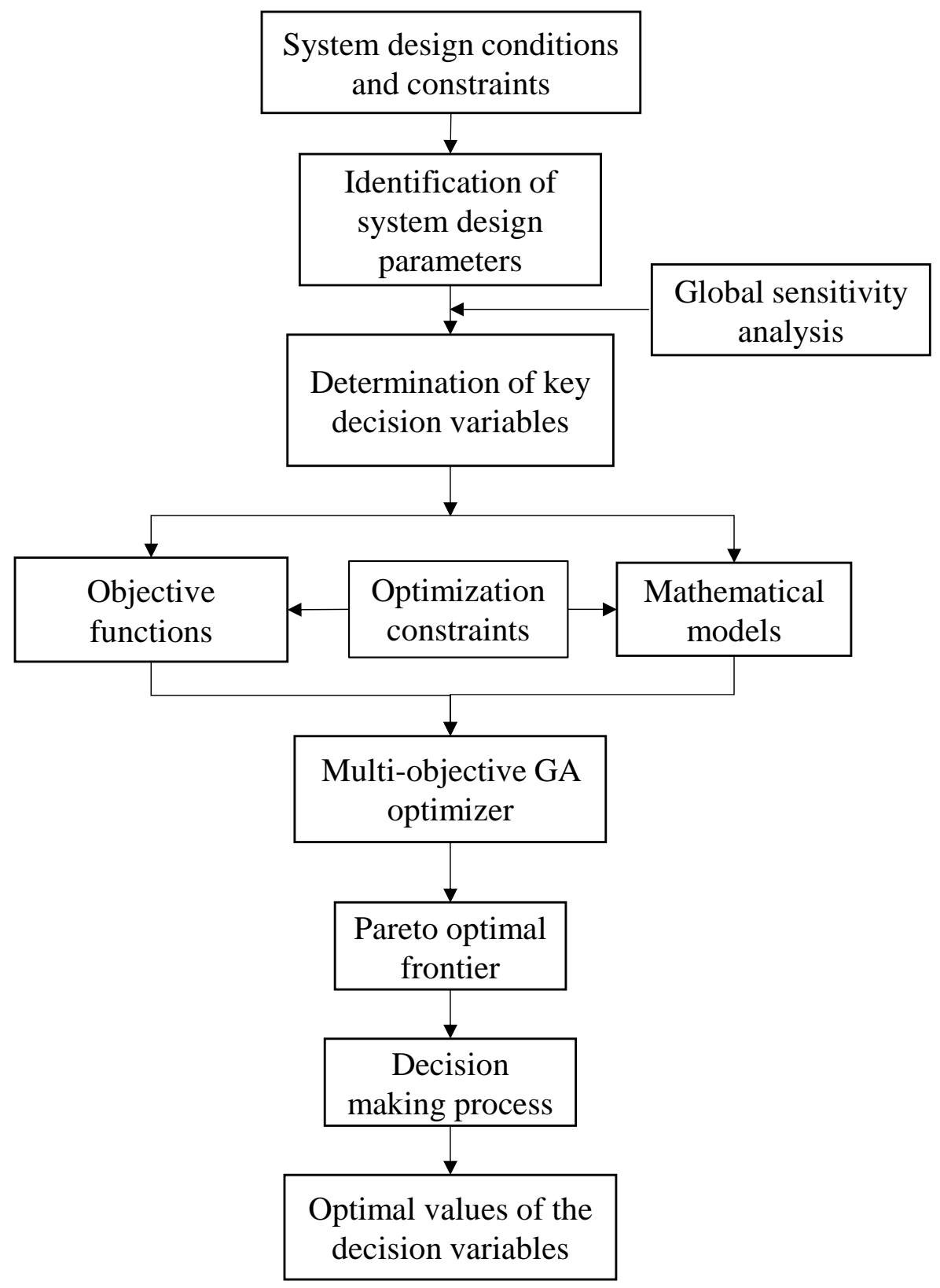

Fig. 1 Outline of the design optimization strategy. 


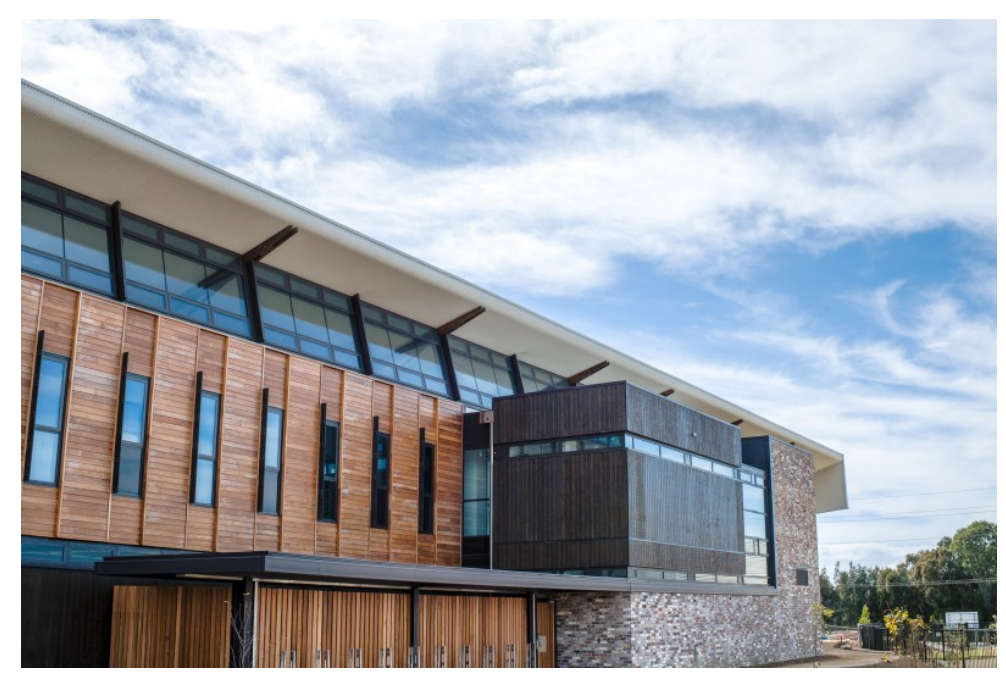

a) Building concerned in Case I.

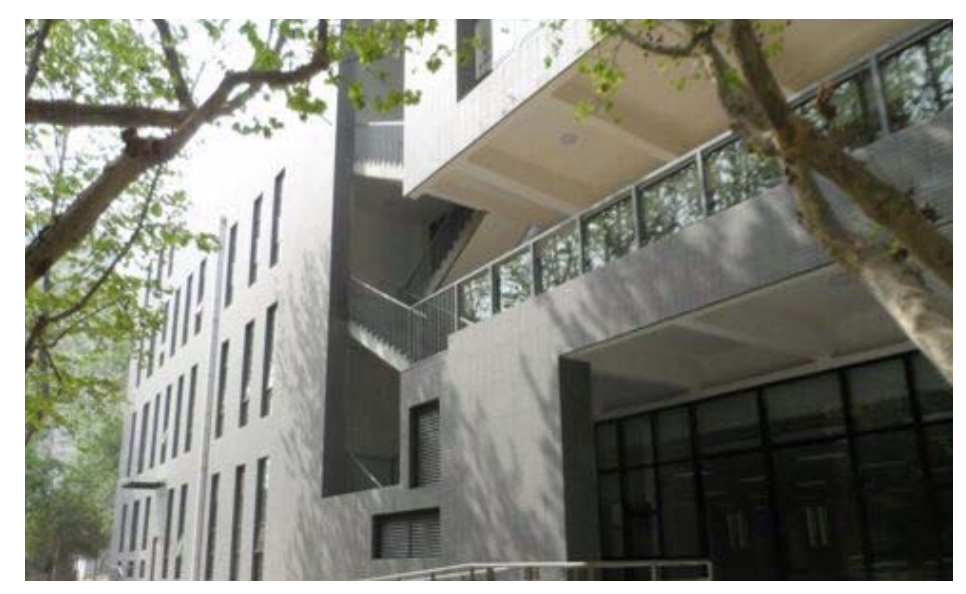

b) Building concerned in Case II.

Fig. 2 Renders of the buildings concerned in this study.

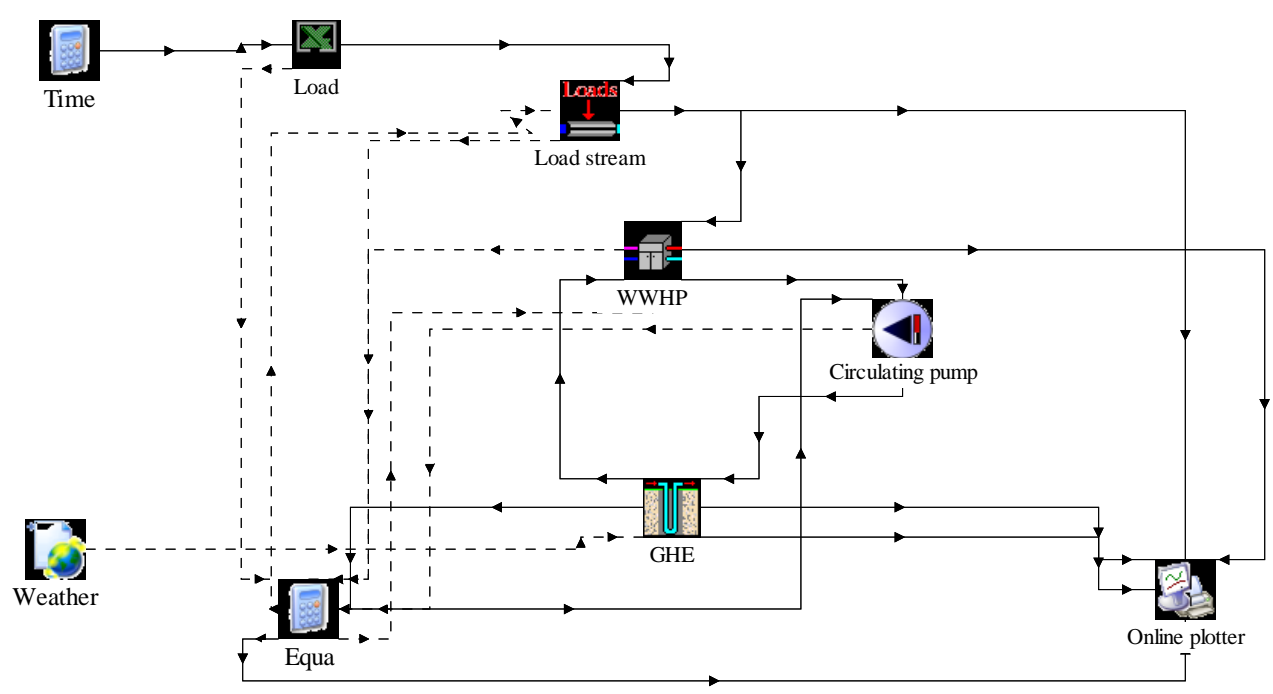

Fig. 3 Simulation platform developed by TRNSYS. 


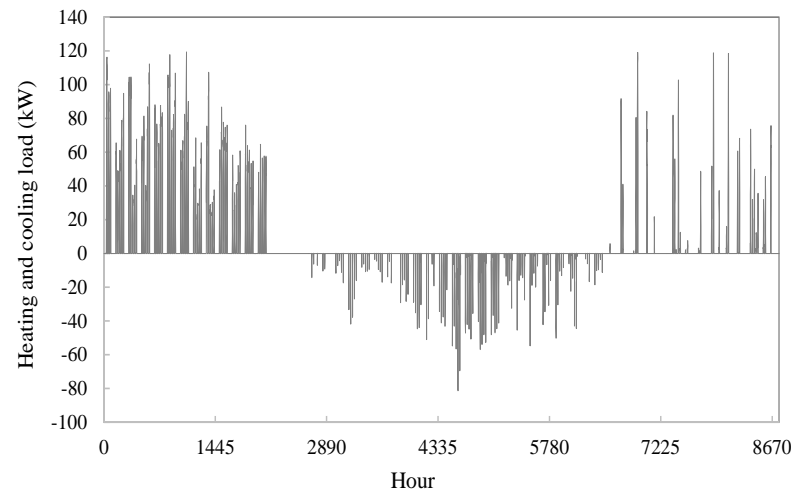

a) Building load profile

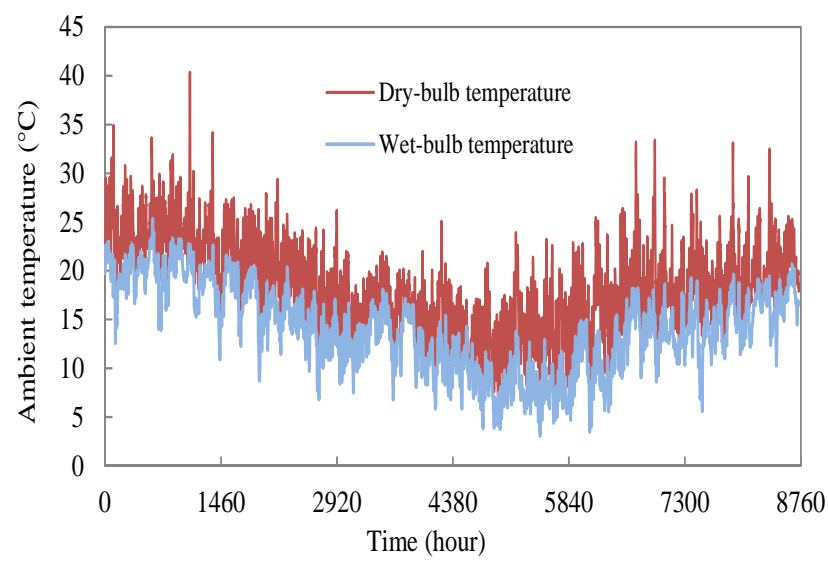

b) Sydney weather condition

Fig.4 Building heating and cooling load profiles and weather conditions - Case I 


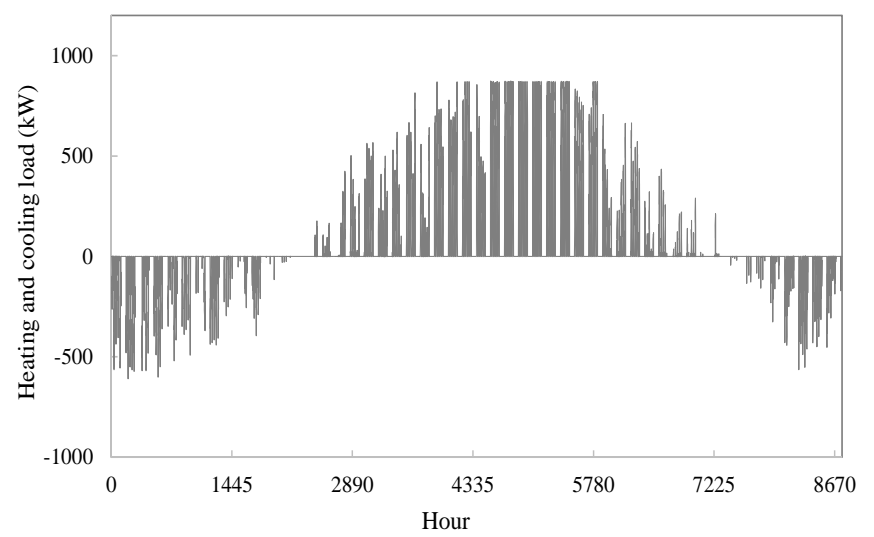

a) Load profile of the areas conditioned by the GSHP

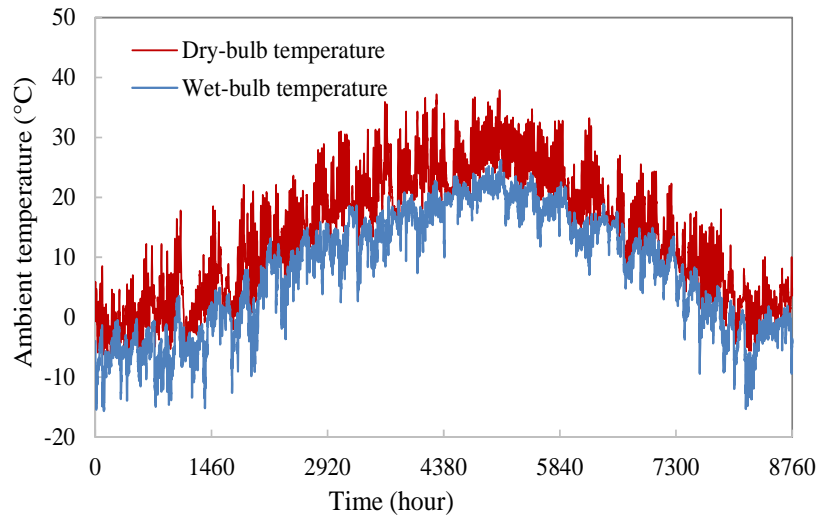

b) Xi'an weather condition

Fig. 5 Load profiles of the areas conditioned by GSHP and weather conditions - Case II

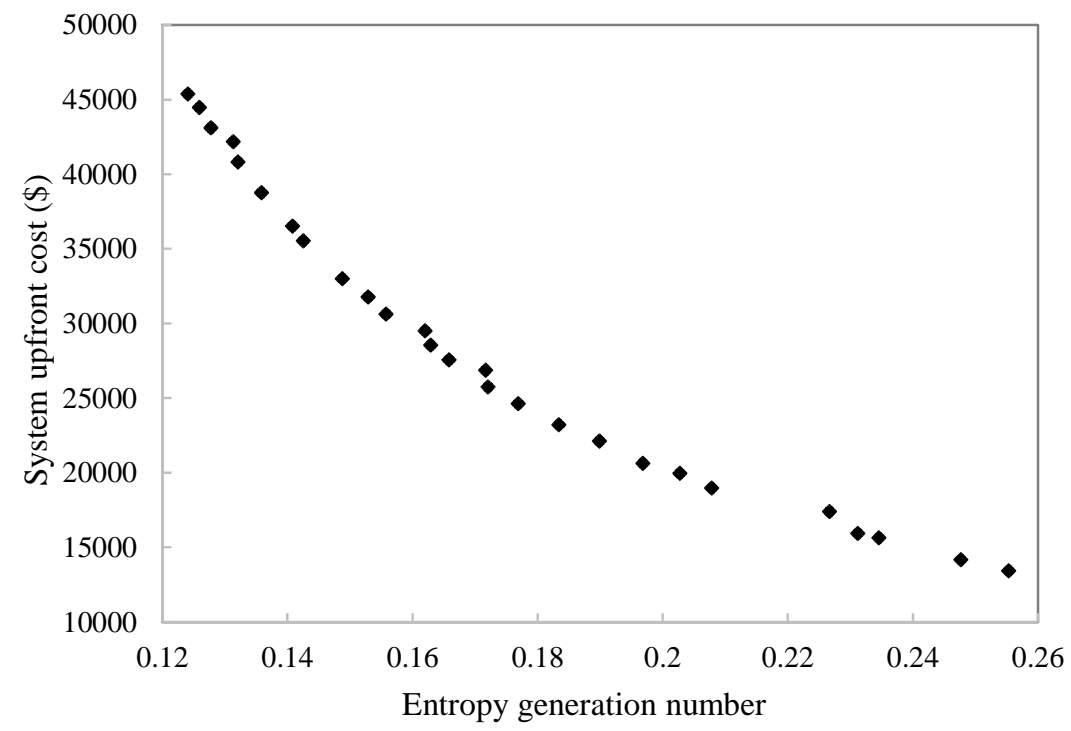

Fig. 6 Illustration of the Pareto optimal frontier identified - Case I. 


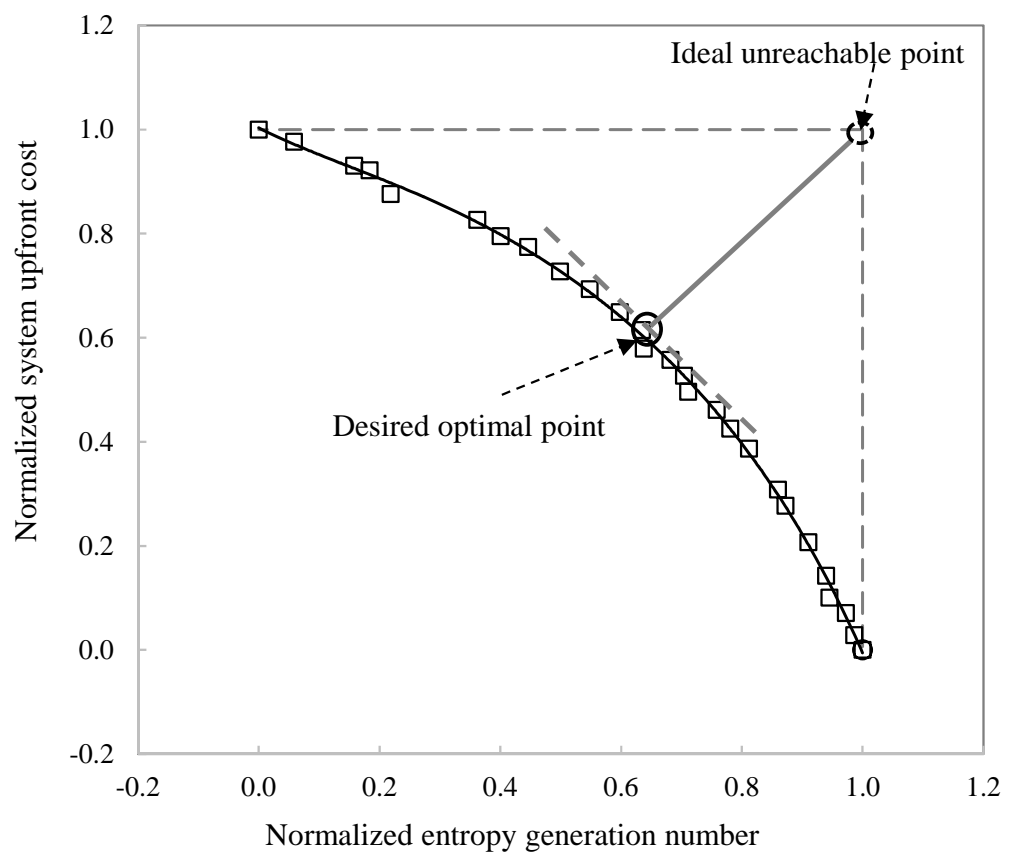

Fig. 7 Normalized Pareto frontier and determination of the final solution - Case I.

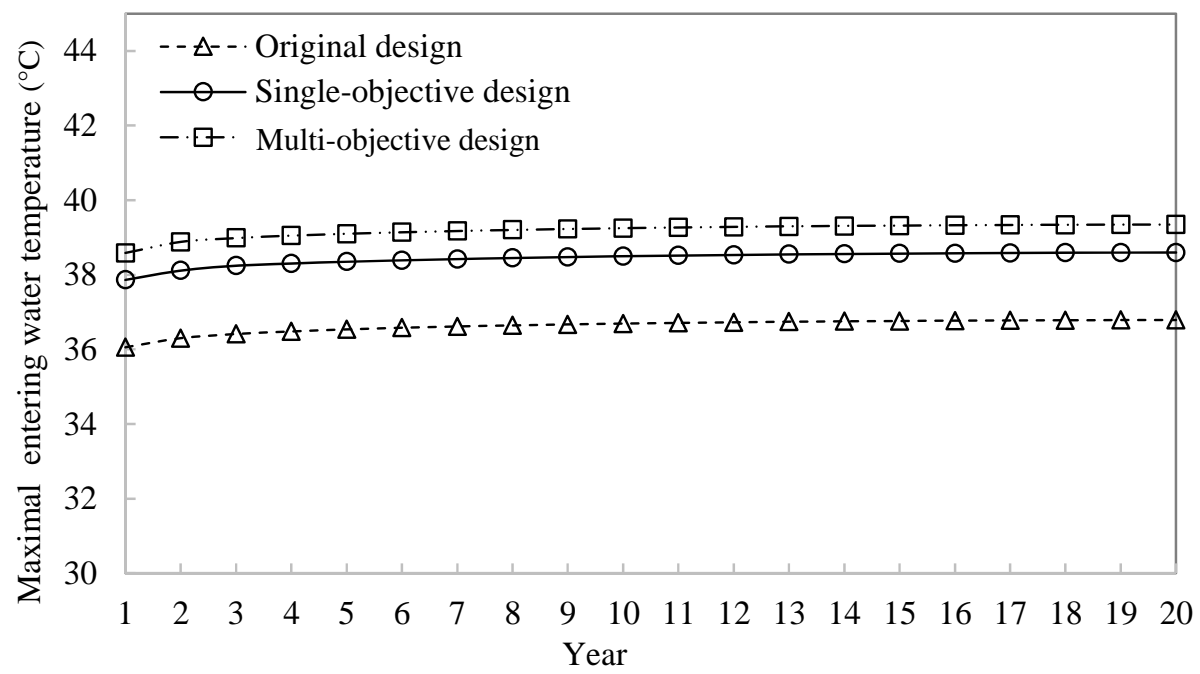

Fig. 8 Annual maximum entering water temperature to the water-to-water heat pump - Case I. 


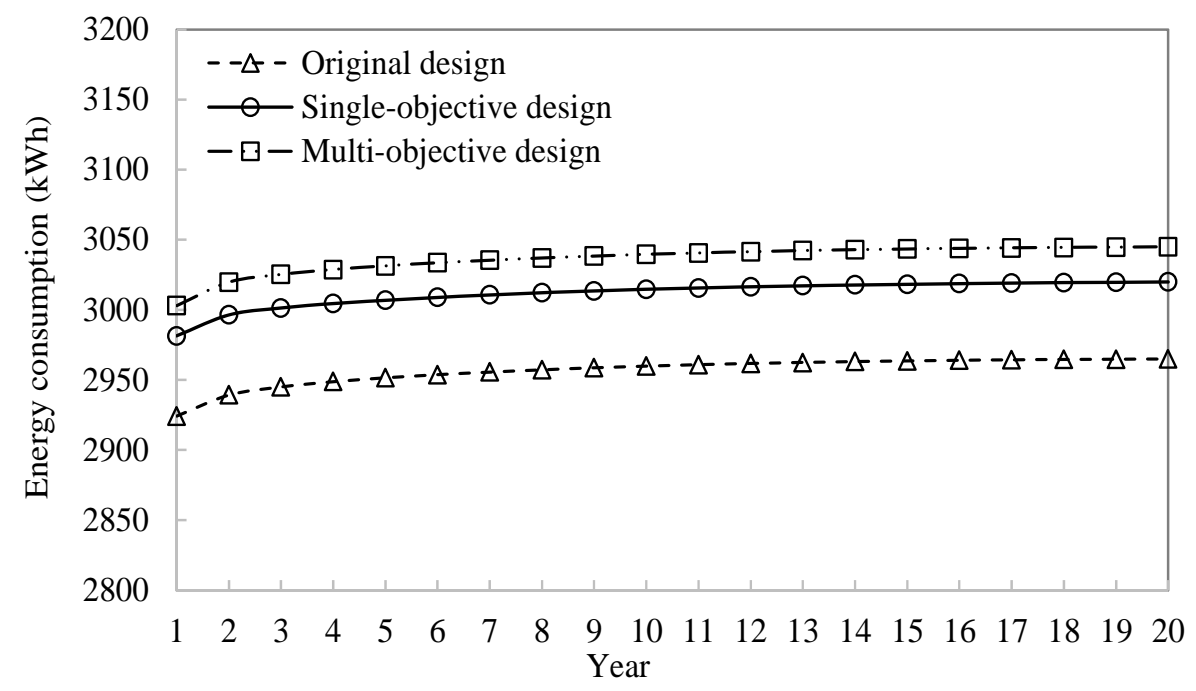

Fig. 9 Annual energy consumption of the GSHP concerned - Case I.

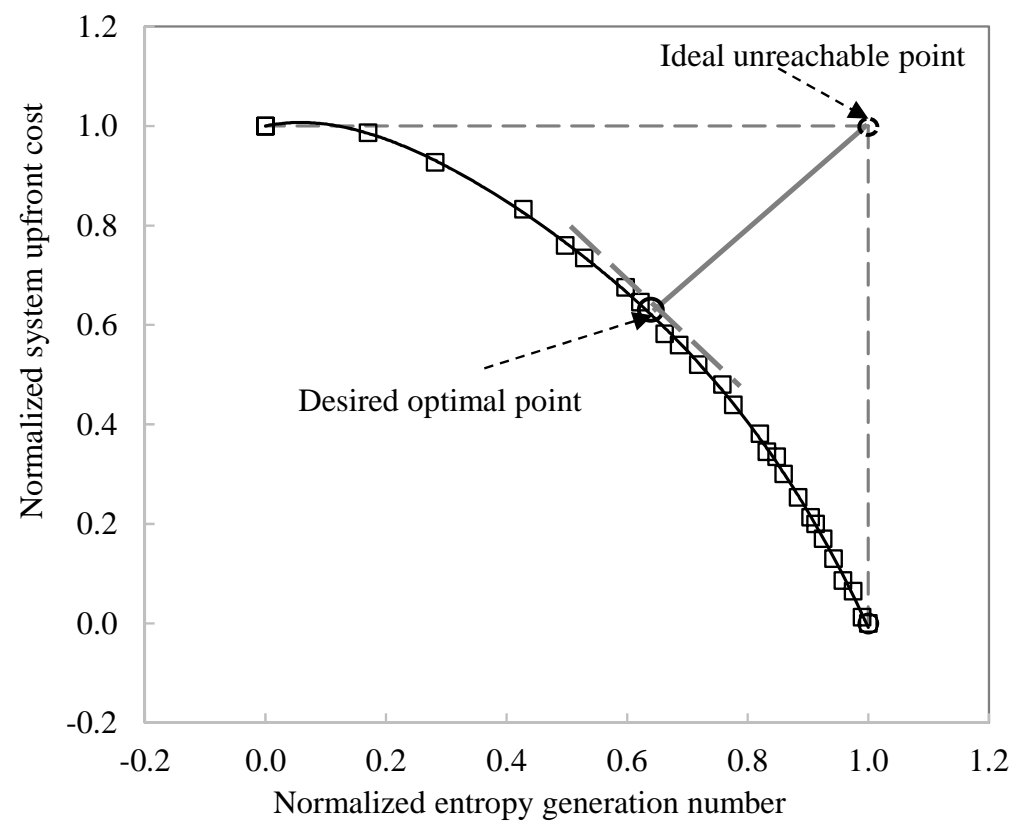

Fig. 10 Normalized Pareto frontier and determination of the final solution - Case II. 


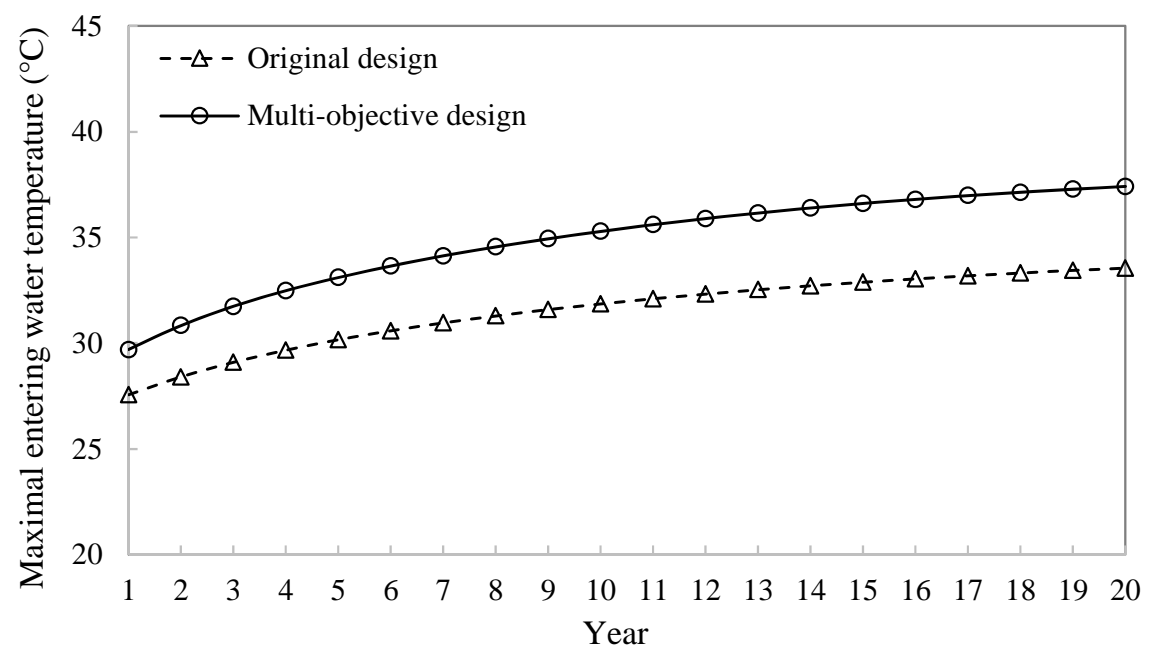

Fig. 11 Annual maximum entering water temperature to the water-to-water heat pumps -

Case II.

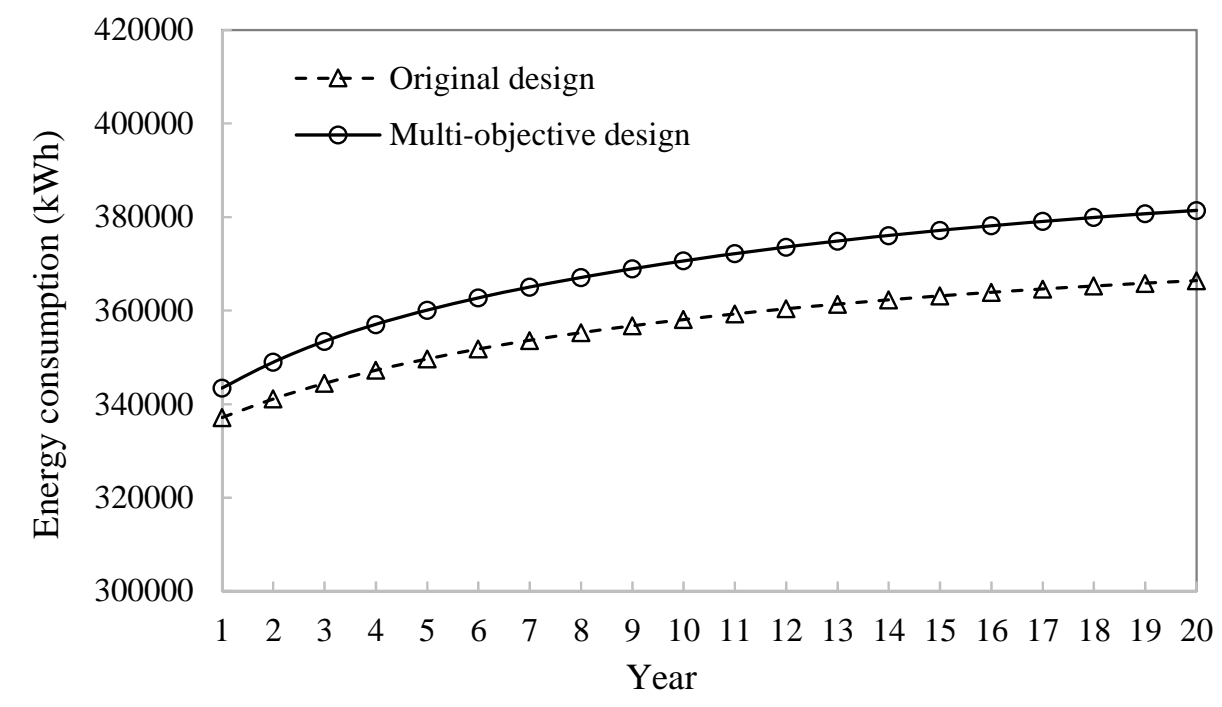

Fig. 12 Annual energy consumption of the GSHP concerned - Case II. 